\title{
Do estado de natureza ao governo civil em John Locke
}

\author{
Adyr Garcia Ferreira Netto ${ }^{1}$
}

\section{Resumo}

\begin{abstract}
No estado de natureza, situação em que segundo a doutrina contratualista o homem ainda não instituiu o governo civil, John Locke entende que os indivíduos são iguais, independentes e estão plenamente livres para decidir suas ações, dispor de seus bens e regular os semelhantes que possam vir a ofender os seus direitos naturais de acordo com seu próprio arbítrio, sendo permitido usar de qualquer meio para salvaguardar suas vidas, liberdade, saúde e posses. No entanto, a vida neste estado natural, implica na incerteza e insegurança da manutenção de próprios direitos, pois o homem é exposto constantemente à violação de sua intimidade e domínios, uma vez que todos são reis absolutos em suas decisões e julgam de acordo com seus valores, sempre em causa própria. Este julgamento, ainda que de forma correta, não dispõe de nenhum poder social instituído que sustente e dê subsídios para execução de sua sentença. O homem, então, renuncia esta condição de liberdade pelo aparente paradoxo da sujeição e submissão ao domínio de outro poder instituído pelo consenso entre os indivíduos, a fim de estabelecer a própria liberdade. Isto somente será possível em uma sociedade politicamente organizada e regulada por uma instituição comum a todos, que supra as carências e deficiências do estado de natureza, garantindo-lhes a conservação da propriedade, finalidade precípua para os homens se unirem em sociedades políticas e se submeterem a um governo, dando-Ihes leis claras e conhecidas, um magistrado imparcial e um poder legítimo para fazer valer a execução de sua sentença.
\end{abstract}

Palavras-Chave: Estado de natureza; Liberdade; Propriedade e governo civil.

\section{Introdução}

O estado de natureza que pressupõe um estágio hipotético da evolução política, dando as origens às instituições das sociedades modernas, sempre será objeto de estudo das ciências humanas. A possibilidade de poder considerá-la como um paradigma, próximo de uma realidade, conduz a uma importante premissa para a compreensão da política e da legitimidade do poder. Não se trata de considerar o estado de natureza como um dado de fato para entender como se desdobrou os acontecimentos históricos, mas reconhecer que esta condição hipotética é possível e perfeitamente válida.

1 Mestrando em Direito Negocial - UEL/2007. adyr@sercomtel.com.br 
Atualmente é comum afirmar que existe no plano internacional um estado de natureza entre países por não haver um ordenamento jurídico internacional que possa legitimamente impor sanções entre os estados nacionais.

[...] espero que os dirigentes mundiais modernos tenham a mesma visão, a mesma sabedoria daqueles que, no passado, construíram um contrato social, pois, na verdade, o que nós estamos precisando é de um contrato social no plano internacional (AMARAL, 2002, p. 97).

Dentre as diversas teorias que se propõem a entender o estado natural do homem e sua transição à uma sociedade institucionalmente organizada, este artigo elege e expõe a filosofia do Inglês John Locke, pela grande influência que exerceu na formação social, política e jurídica na sua época, através da proposta de liberdade do indivíduo, cuja teoria provou grande resistência na Europa dos séculos XVII e XVIII, em razão da predominância do poder da monarquia.

O ideal filosófico e político de Locke, sua linha de pensamento e formação intelectual, são frutos da educação familiar (seu pai era favorável ao parlamentarismo) e dos acontecimentos históricos que o cercavam (razão como pressuposto científico - liberalismo econômico e social), influenciando o seu pensamento a contemplar uma filosofia que valoriza a liberdade individual, tendo-a como base para explicar a proposição e justificativa da formação de um Estado Civil. Combateu a idéia de sucessão de poder através da hereditariedade, defendida pela monarquia como sendo legítima por força da filiação direta dos reis em relação a Deus.

O problema proposto neste trabalho, diz respeito a razão pela qual a sociedade deve abandonar o estado de natureza e criar através de um pacto social o governo civil, pressupõe um estado primitivo (não no sentido cronológico, mas evolutivo, pois John Locke admite a existência desta condição social nos tempos hodiernos) em que o homem procura organizar-se socialmente a fim de superar algumas dificuldades que inviabilizam o convívio entre os indivíduos sem que haja injustiças.

Partindo do pressuposto da existência deste estado natural, como o homem se organiza a fim de suprir suas necessidades de justiça, ou para garantir seus direitos? 
O presente texto pretende descrever a concepção filosófica de Locke ao tratar da transição do Estado de Natureza humana até a consolidação de um Governo Civil, mostrando seus problemas e necessidades e as razões pelas quais se devem superá-las.

Analisa o conceito de propriedade, o aparecimento do dinheiro e finalmente o resultado final que é a introdução do governo civil através do pacto social, ou o acordo entre os homens que dá legitimidade ao poder deste governo.

\section{0 estado anterior a sociedade civil}

\subsection{0 estado de natureza}

Para poder entender os motivos pelos quais o homem criou a sociedade civil, devese considerar como ele vive no estado de natureza ${ }^{2}$, ou seja, no estado em que se encontra antes da criação do governo, para que diante deste cenário, seja possível compreender as razões e as necessidades que levam as pessoas a organizar o convívio com seus semelhantes e superar as dificuldades (II, § 4$)^{3}$.

John Locke descreve o estado de natureza como um lugar onde não há governo exercendo qualquer poder sobre as pessoas como ocorre nas sociedades políticas, pois ainda que naturalmente o homem não devesse prejudicar a outrem em sua vida, saúde, liberdade ou posses (II, §6), não há uma lei conhecida por todos ou imposta pelos homens para que sirva de parâmetro. Cada um está livre para decidir suas ações e colocar a disposição tudo que possui da forma que achar correto ou conveniente (II, § 4), sem estar vinculado a nenhuma outra vontade ou permissão para agir de tal forma.

Assim, como não há um poder concentrado nem uma jurisdição definida que possa dar poder a um indivíduo sobre os outros, este estado sem sujeição e nem subordinação, pressupõe a perfeita liberdade e igualdade.

[...] perfeita liberdade para regular suas ações e dispor de suas posses e pessoas do modo como julgarem acertado dentro dos limites da lei da natureza, sem pedir licença ou depender da vontade de qualquer outro homem. E também um estado

2 O verbo viver está no presente, pelo fato de John Locke admitir que o Estado de natureza é uma condição possível concomitante com as sociedades modernas, não é uma questão somente cronológica, e sim evolutiva, como os índios das florestas americanas que ainda hoje não tem, segundo Locke, uma sociedade civilmente organizada.

3 (II, §4) significa parágrafo quarto do segundo tratado. 
de igualdade, em que é recíproco todo o poder e jurisdição, não tendo ninguém mais que outro qualquer (LOCKE, 1998, p. 382).

O homem é o senhor e amo de todas as suas manifestações, mas também é igual aos outros, que são criaturas da mesma espécie e posição, sendo assim, independentes, iguais e livres, para dentro dos limites da lei da natureza decidir, conforme já exposto, suas ações, disporem de seus bens e regularem as demais pessoas. No entanto, John Locke afirma que este estado embora seja de perfeita liberdade e igualdade, não é um estado libertino ou licencioso, não podendo o homem destruir as dádivas da natureza em prol apenas da sua ilimitada liberdade, mas apenas para poder preservar a si próprio, ou por alguma necessidade que venha justificar tal atitude (II, § 6).

Cada um está obrigado a preservar-se, e não abandonar a sua posição por vontade própria; logo, pela mesma razão, quando sua própria preservação não estiver em jogo, cada um deve, tanto quanto puder, preservar o resto da humanidade, e não pode, a não ser que seja para fazer justiça a um infrator, tirar ou prejudicar a vida ou o que favorece a preservação da vida, liberdade, integridade ou bens de outrem (LOCKE, 1998, p. 385).

Então, Locke entende que o estado de natureza é um estado de perfeita liberdade e igualdade, mas que está submetido a algumas leis de responsabilidade dos próprios homens, que são as leis da natureza (II, §s. 6,7,8,9,10,11): Não prejudicar a outrem em suas vidas, saúde, liberdade ou posses.

De outra forma, qual seria o sentido da natureza impor algumas regras para a existência do ser humano, se não houvesse alguém para executá-las? Ora, este alguém é o próprio homem, se ele herdou as regras naturais cabe a ele cumpri-las.

E para que todos os homens sejam impedidos de invadir direitos alheios e de prejudicar uns aos outros, e para que seja observada a lei da natureza, que quer a paz e a conservação de toda a humanidade, a responsabilidade pela execução da lei da natureza é, nesse estado, depositada nas mãos de cada homem, pelo que cada um tem o direito de punir os transgressores da dita lei em grau que impeça sua violação ${ }^{4}$. Pois a lei da natureza seria vã, como todas as demais leis que dizem respeito ao homem neste mundo, se não houvesse alguém que tivesse, no estado de natureza, um poder para executar essa lei e, com isso, preservar os inocentes e conter os transgressores. E se qualquer um no estado de natureza pode punir a outrem, por qualquer mal que tenha cometido, todos o podem fazer, pois, nesse estado de perfeita igualdade, no qual naturalmente não existe superioridade

\footnotetext{
4 Grifo nosso.
} 
ou jurisdição de um sobre outro, aquilo que qualquer um pode fazer em prossecução dessa lei todos devem necessariamente ter o direito de fazer (LOCKE, 1998, p. 385-386).

John Locke admite então, que o homem pode ter um poder sobre o outro no estado de natureza (II, § 8), mas um poder de executar as leis da natureza, repelindo as injustiças de modo proporcional à agressão (e consequentemente a uma restrição) de determinadas atitudes ofensivas, justificando a única situação legal dele poder fazer mal a outro, é o que Locke chama de castigo.

$\mathrm{Na}$ hipótese de algum indivíduo estar transgredindo deliberadamente as regras naturais, ele torna-se perigoso para a humanidade, pois está ao mesmo tempo ofendendo a perfeita liberdade e igualdade (liberdade restringida pelas leis naturais e igualdade quando trata seu semelhante desigualmente).

Ao imaginar o estado de natureza desta forma, John Locke confere aos indivíduos alguns direitos, que são (II, § 11): 1) o de castigar o crime e preveni-lo e, 2) reivindicar ou obter reparação do dano causado, que caberá somente a parte prejudicada.

Estes direitos derivam do legítimo direito de auto - conservação, quando o homem mata um assassino no estado de natureza, ele está evitando também que outros cometam o mesmo erro, para isso, Locke destaca a passagem bíblica no Segundo Tratado sobre o Governo: Aquele que derramar o sangue do homem, pelo homem terá seu sangue derramado (LOCKE, 1998, p.389).

Se o homem pode legalmente tirar a vida de outro no estado de natureza quando a situação exigir, poderá ele também castigar de maneira proporcional a outros delitos menores, bastando que a punição seja suficiente, ou cuja severidade mostre ao transgressor que sua atitude ofensiva é um mau negócio, dando-lhe causas para o arrependimento e servindo de lição para que outros não cometam os mesmos erros. (II, § 12). Peter Laslett (apud LOCKE, 1998, pp. 142-143) resume:

O estado de natureza é simplesmente a condição na qual o poder executivo da lei da natureza se mantém exclusivamente nas mãos de indivíduos e não se tornou comunal. Pode-se deduzir que tenha sido esta a condição original de toda a humanidade, pois onde quer que se encontre uma autoridade coletiva estabelecida e permanente, descobre-se sempre que se trata do resultado da reflexão dos homens e das medidas que deliberam a fim de garantir e estabelecer o domínio da racionalidade e os dispositivos da lei natural. 


\subsection{A superação do estado de natureza}

Ao descrever o estado de natureza como este ambiente de perfeita liberdade e igualdade entre os indivíduos, e que cada um tem o legítimo direito de decidir suas ações, defender a conservação da espécie e as leis da natureza com castigos aos infratores proporcionais aos delitos cometidos e com severidade suficiente para ele entender que agiu errado e também para servir de lição para os demais, Locke atribui ao homem o poder executivo da lei da natureza, mas também uma responsabilidade que pode ser muito perigosa, pois ele admite que:

[...] a natureza vil, a paixão e a vingança os levarão longe demais na punição dos demais, da qual nada resultará além de confusão e desordem e, portanto, Deus certamente designou o governo para conter a parcialidade e a violência dos homens. Admito sem hesitar que o governo civil é o remédio adequado para as inconveniências do estado de natureza, que certamente devem ser grandes quando aos homens é facultado serem juizes em suas próprias causas, pois é fácil imaginar que aquele que foi injusto a ponto de causar injúria a um irmão dificilmente será justo o bastante para condenar a si mesmo por tal (LOCKE, 1998, p. 391-392).

Locke então observa que por ser movido pelas suas paixões e por valores de juízo próprios de sua subjetividade, o homem jamais poderia julgar corretamente o seu transgressor sem trazer injustiças, pois como ser juiz de sua própria causa sem ser parcial?

Ora, se ainda um homem castigasse outro por uma causa alheia, ou seja, na hipótese de um indivíduo defender o direito de um terceiro ofendido, qual seria o critério para aplicar uma pena proporcional?

Então surgem alguns problemas:

1) para obter um critério de justiça, esta pena seria aplicada igualmente a todos os outros casos semelhantes, partindo do pressuposto da perfeita igualdade do estado de natureza?

2) Se todos os homens têm legitimidade para aplicar a lei, os critérios de proporcionalidade serão diversos tanto quanto forem os juizes, ou seja, não há um juiz conhecido que todos poderiam crer na sua imparcialidade;

3) Ainda que implicitamente haja leis no estado de natureza que devem ser seguidas por todos, onde elas estão positivadas? Aonde procurá-las se tenho dúvidas em 
relação a elas? Se não há uma lei sequer de conhecimento geral, como saberei se estou infringindo-a ou não?

4) Na hipótese de um indivíduo fazer justiça em prol da conservação da espécie humana como se pressupõe no estado de natureza, quem daria subsídios ou o que daria poder ou apoiaria sua decisão de aplicar os castigos? Se um homem matar outro por este ter assassinado, aquele que fez justiça também não estaria sujeito de sofrer o castigo da pena de morte por um terceiro?

O estado natural é um estado de liberdade, mas não de lincenciosidade (II, § 6)!

Esta licença irrestrita dos homens traz a instabilidade e insegurança que implicam para John Locke, a necessidade de institucionalizar uma ordem superior que dê subsídios legais para que se possa disciplinar as relações entre as pessoas, trazendo harmonia à sociedade ao limitar as ações dos homens e àquelas situações em que a ilimitada liberdade possa trazer perigo ao convívio entre os homens. A esta organização institucional John Locke chama de governo civil.

Ora, se é inerente à natureza humana o convívio em sociedade, como admite Locke, [...] tendo feito o homem uma criatura tal que, segundo seu próprio juízo, não the era conveniente estar só, colocou-o sob fortes obrigações de necessidade, conveniência e inclinação para conduzi-lo para a sociedade (LOCKE, 1998, p. 451). E se o homem nasce livre igual e independente, não estando então sob a jurisdição de outro, ele não poderá ser privado destes direitos, a não ser que ele próprio consinta com isto, ou seja, como criar um poder superior que venha não ferir estes direitos naturais?

A resposta está no pacto social, num acordo entre as pessoas para que possam viver em harmonia e garantir seus direitos (II, § 95).

A única maneira pela qual uma pessoa qualquer pode abdicar de sua liberdade natural e revestir-se dos elos da sociedade civil é concordando com outros homens em juntar-se e unir-se em uma comunidade, para viverem confortável, segura e pacificamente uns com outros, num gozo seguro de suas propriedades e com maior segurança contra aqueles que dela não fazem parte (LOCKE, 1998, p. 468).

O pacto social então une por consentimento os homens para formar um corpo político sob um governo único, que estará submisso à determinação da maioria, que de 
forma diferente, este contrato não teria sentido algum (II, §s 96, 97). Assim, as pessoas criam um poder legítimo para governá-las.

\begin{abstract}
Deve-se entender, portanto, que todos aqueles que abandonam o estado de natureza para se unirem a uma comunidade abdicam, em favor da maioria da comunidade, a todo o poder necessário aos fins pelos quais eles se uniram à sociedade, a menos que tenham expressamente concordado em qualquer número superior à maioria. E isso ocorre simplesmente pela concordância em unir-se em uma sociedade política, em que consiste todo o pacto existente, ou que deve existir, entre os indivíduos que ingressam num corpo político ou o formam. Por conseguinte, o que inicia e de fato constitui qualquer sociedade política não passa do consentimento de qualquer número de homens livres capazes de uma maioria no sentido de se unirem e incorporarem a uma tal sociedade. $E$ é isso, e apenas isso, que dá ou pode dar origem a qualquer governo legítimo no mundo (LOCKE, 1998, p.472, grifo nosso).
\end{abstract}

Eis como o homem dá seu primeiro passo para superar os problemas do estado de natureza: o pacto social! ${ }^{5}$

Agora, o homem se reúne e cria legitimamente seu poder governamental dando origem a sociedade política, mas ainda que este novo estado traga estabilidade ao convívio entre os homens, John Locke (1998, p. 495) destaca como seu fim principal, a propriedade, ou seja, tudo aquilo que a ele pertença.

E não é sem razão que ele procura e almeja unir-se em sociedade com outros que já se encontram reunidos ou projetam unir-se para a mútua conservação de suas vidas, liberdades e bens, aos quais atribuo o termo genérico de propriedade (LOCKE, 1998, p. 495).

5 É então através deste pacto que o homem cria seu governo político legítimo, mas ainda é interessante destacar que embora o estado de natureza seja superado, Locke acredita que é preferível a vida livre e igual daquele estado inicial do que o governo civil em forma de monarquia: [...] os monarcas absolutos são apenas homens e, se o governo há de ser o remédio aos males que necessariamente seguem os homens juízes em suas próprias causas, razão pela qual o estado de natureza não pode ser suportado, gostaria de saber que tipo de governo é esse e em que é ele melhor que o estado de natureza, no qual um homem, no comando de uma multidão, tem a liberdade de ser juiz em causa própria e pode fazer a todos os seus súditos o que bem lhe aprouver, sem que qualquer um tenha a mínima liberdade de questionar ou controlar aqueles que executam o seu prazer. Em que todos devem submeter-se a ele no que quer que faça, sejam os seus atos ditados pela razão pelo erro ou pela paixão? Muito melhor é o estado de natureza, no qual os homens não são obrigados a se submeterem á vontade injusta de outrem e no qual aquele que julgar erroneamente em causa própria ou na de qualquer outro terá de responder por isso ao resto da humanidade (LOCKE, 1998, p. 392). 


\subsection{A propriedade}

No Segundo tratado sobre o governo civil, o conceito de propriedade para John Locke é extremamente importante, pois atribui à ela as principais justificativas para o homem abdicar da liberdade do estado de natureza para submeter-se ao governo civil.

O fim maior e principal para os homens unirem-se em sociedades políticas e submeterem-se a um governo é, portanto, a conservação de sua propriedade (LOCKE, 1998, p. 495).

Antes de conceituá-la, é preciso entender que o direito de propriedade é um corolário derivado das leis naturais, e o homem por ter o direito e dever de preservar a sua vida, pertencerá a ele sua alimentação, bebida, e tudo aquilo que a natureza lhe oferece para a sua subsistência.

A posse destes recursos antecede e independe da sociedade civilmente organizada, pois estes são imprescindíveis à perpetuação da vida. Ora, se os homens têm direito a alguns recursos naturais, como determinar qual recurso pertence a quem, se todos têm direito as coisas que a natureza oferece? A resposta desta questão é uma das grandes razões para que os homens institucionalizem um poder legítimo que possa garantir os seus direitos, ou seja, aquilo que o homem conquista e então possui por direito deverá ser garantido por um poder superior, como um governo civil.

Enfim, qual é a determinante que dá ao homem o direito de propriedade sobre algo? John Locke afirma que é o trabalho de seu corpo e a obra de suas mãos.

Se existe no estado de natureza uma fruta, ela pertence a todos, mas uma vez que o indivíduo a colhe e guarda para si, acrescenta algo personalíssimo ao fruto: A sua força de trabalho, ou seja, a diferença entre a fruta que está em seu cesto e a que está intacta na natureza é exatamente o trabalho empregado pelo indivíduo que, neste ato lhe confere direito legítimo de propriedade sobre aquele fruto.

No entanto, Locke entende que esta propriedade legítima e inquestionável, só se dá quando o homem retira da natureza algo para sua subsistência, para apenas usufruir de forma parcimoniosa, pois embora haja abundância, os recursos não são infinitos, e o que exceder sua parte, passa a pertencer aos outros, pois a subsistência é um direito de todos.

Assim como os frutos colhidos, os animais abatidos para sua alimentação e tudo aquilo que retirar para sua subsistência através da sua força de trabalho é de sua posse. $\mathrm{A}$ 
propriedade no estado de natureza também se estende às terras, que o homem poderá arar, plantar, aprimorar, cultivar e colher, sempre observando a condição da subsistência, sem que seja prejudicial a qualquer outro homem, assim, a natureza põe alguns limites interessantes à propriedade, que são o trabalho e a conveniência de vida.

Como bem observa John W. Yolton (1996, p. 210), o significado para John Locke de adicionar algo à natureza, como exemplo em relação à terra, é enfatizado da seguinte forma:

\begin{abstract}
Ao entregar a terra a toda humanidade, Deus 'ordenou também aos homens que trabalhassem'; Deus ordenou que o homem 'dominasse a terra', isto é, que 'a melhorasse para benefício da vida e dispusesse do que the pertencia, o seu trabalho' (II, § 32). Arrotear a terra adiciona-lhe algo que já é propriedade do agricultor, o seu trabalho. Ele também tem propriedade em sua pessoa, pelo que pessoa e trabalho se conjugam para adquirir propriedade adicional (YOLTON, 1996, p. 210).
\end{abstract}

Mas a simples posse das coisas materiais traz apenas um conceito estrito da propriedade, e John Locke foi além, pois será que apenas pela incerteza da posse dos seus objetos que o homem deve sair do estado de natureza? O que é então propriedade para Locke?

Peter Laslett (apud LOCKE, 1998, p. 150) faz a seguinte observação:

Será lícito nos queixarmos de que Locke não deixa suficiente claro qual definição de propriedade ele utiliza em cada contexto. Mas o fato de ele admitir que a propriedade material, a propriedade dos objetos naturais misturados com 0 trabalho, representasse vários ou todos os direitos abstratos do indivíduo...

A propriedade então, diz respeito a uma condição inerente ao indivíduo, é algo que faz parte dele, é pessoal que se distingue dos demais, ainda que tudo da natureza seja para todos, há direitos inerentes a pessoa. Em outras palavras, quando ele agrega a força abstrata do seu trabalho nos recursos da natureza, está transferindo algo que pertence somente a ele e a mais ninguém, acrescentou no fruto, na caça, algo que nem deus tinha colocado: $O$ seu trabalho. Também a sua liberdade e igualdade fazem parte de sua propriedade, porque parte de si.

Pois a propriedade, para Locke, parece simbolizar os direitos em sua forma concreta, ou talvez, melhor que isso, estabelecer o tema tangível dos poderes e atitudes de um indivíduo. É porque podem ser simbolizados enquanto propriedade, 
enquanto algo que o homem pode conceber como distinguível de si próprio (LASLETT apud LOCKE, 1998, p. 150).

A interpretação de propriedade em John Locke baseada unicamente no Segundo Tratado não é clara, mas pode-se afirmar com segurança que seu propósito principal é dar legitimidade de posse de algo para alguém, e garantir sua igualdade e liberdade, assim, justificando a criação do governo civil para salvaguardar este direito.

Se adquirirmos algo de forma legal, este direito deverá ser garantido, ou seja, as leis civis deverão regulamentar as propriedades particulares do homem em sociedade estabelecidas no pacto social, e assim a propriedade ganha sua importância, para o governo protegê-la das ameaças do estado de natureza.

Quando Locke trata do acordo entre os homens para regular suas propriedades, dando a cada um aquilo que the é devido em função da força do seu trabalho, lembra que o valor intrínseco dos recursos naturais adquiridos e transformados para seu uso, depende da sua utilidade e nada mais do que isto (II, § 37), mas ainda adverte que com o advento da criação do dinheiro, as pessoas poderão trocar algo que conseguiram trabalhando por este intermediário de troca.

Um fruto que o homem colheu poderá apodrecer amanhã, e assim, seu trabalho de colhê-lo também perecerá, mas se puder trocá-lo por algo que perdure no tempo sem depreciar seu valor, o homem então poderá além de conservar a sua força de trabalho, armazenar de tal forma que terá um acúmulo de propriedades.

Como foi observado, pertence ao homem somente aquilo que for estritamente necessário para a sua sobrevivência, pois ainda que abundante, os recursos naturais são de todos, se o homem colher frutas além das suas necessidades, estas provavelmente apodrecerão e deixariam de servir de alimento para outrem, assim, aquele que colheu os excessos estaria contrariando as leis naturais invadindo direitos dos outros.

No entanto, e se um indivíduo colhesse frutas em excesso e trocasse aquilo que para ele for dispensável por outras coisas duráveis que poderiam ser consumidas ao longo do tempo? Ele não causaria dano algum nem estaria desperdiçando a reserva natural que é de todos, então, o exagero nos limites da propriedade justa de cada um não está na extensão de suas posses, mas sim no perecimento inútil de qualquer parte delas (II, § 46). 
Se ainda por consenso entre as pessoas, o excedente colhido na natureza pudesse ser trocado por uma pedra, que é durável e não perece, e posteriormente eu pudesse reaver a quantidade equivalente daquele excesso em permuta com a pedra que guardei, também não haveria desperdício algum, e poderia dessa forma armazenar o esforço do meu trabalho transformado em propriedade ao longo do tempo.

É assim que John Locke (1998, p. 426) vê a institucionalização do dinheiro. [...] um instrumento durável que o homem pudesse guardar sem se estragar e que, por consentimento mútuo, os homens aceitassem em troca dos sustentos da vida, verdadeiramente úteis, mas perecíveis.

A importância de se falar no dinheiro no problema que se refere a transição do estado de natureza ao governo civil, é que John Locke por dar tanta importância à propriedade, também vê no dinheiro como um sucedâneo desta, ou seja, o dinheiro dá um título de propriedade sobre as coisas da natureza, e pelo fato de agregar valores como o esforço do trabalho, ele estende ainda mais as condições de posses dos indivíduos, pois as pessoas poderão adquirir maiores quantidades de bens e propriedades diversas.

\section{0 governo civil}

No Segundo Tratado sobre o Governo Civil, John Locke entende que a primeira forma de sociedade que o homem forma é a sociedade conjugal, ou seja, uma união voluntária do homem e da mulher para o fim da procriação. Deverá esta relação ser duradoura para que eles possam sustentar seus filhos até o momento deles poderem mover-se e prover-se por si mesmos, pois a procriação não é um fim em si mesmo, serve para perpetuar a espécie humana, implicando no cuidado com a prole. Embora a união conjugal e a família seja uma forma de sociedade, ela está longe de ser uma sociedade política ou civil (II, § 77).

É inerente a natureza humana o instinto da coletividade, o homem desde tempos imemoriais vive socialmente para em conjunto criar os instrumentos capazes de suprir as necessidades de perpetuação da sua espécie.

Aliado a este instinto, a racionalidade natural do homem diante dos problemas existentes no estado de natureza, concluiu que a criação de um governo civil é o corolário mais lógico e ideal da relação destas premissas. 
O homem cria o governo civil ou a sociedade política quando através do pacto social, entra num consenso e delega poderes para um terceiro, para que ele possa instituído de uma coação legítima, garantir a sua segurança e as suas propriedades. Então, o homem substitui a sua liberdade "irrestrita" e seu poder de empregar a própria força para defenderse a este novo poder, ou seja, para Estado, que poderá dar solução adequada, justa e imparcial para decidir as eventuais diferenças que o convívio em sociedade venha produzir.

A instituição do governo civil é então um remédio que o homem encontrou para solucionar os problemas do estado de natureza. Os indivíduos realizam um pacto social consentindo em delegar poderes a um ente que possa ter subsídios legais, legítimos para usar da força coativa com a finalidade de preservar a sua integridade, seus direitos naturais e especialmente a propriedade sobre seus bens.

Sendo todos os homens, como já foi dito, naturalmente livres, iguais e independentes, ninguém pode ser privado dessa condição nem colocado sob o poder político de outrem sem o seu próprio consentimento. A única maneira pela qual uma pessoa qualquer pode abdicar de sua liberdade natural e revestir-se dos elos da sociedade civil é concordando com outros homens em juntar-se e unir-se em uma comunidade, para viverem confortável, segura e pacificamente uns com os outros, num gozo seguro de suas propriedades e com maior segurança contra aqueles que dela não fazem parte. Qualquer número de homens pode fazê-lo, pois tal não fere a liberdade dos demais, que são deixados, tal como estavam, na liberdade do estado de natureza. Quando qualquer número de homens consentiu desse modo em formar uma comunidade ou governo, são, por esse ato, logo incorporados e formam um único corpo político, no qual a maioria tem o direito de agir e deliberar pelos demais (LOCKE, 1998, p. 468-469).

É importante recordar que John Locke atribui à formação de um governo civil, e a submissão dos homens a ele, um motivo principal: a conservação da propriedade privada! (II, § 124). E propriedade não é um termo estrio: ... a mútua conservação de suas vidas, liberdades e bens, aos quais atribuo o termo genérico de propriedade (II, § 123)

Confiando na força do governo civil, o homem tem agora a superação de uma série de fatores que carece o estado de natureza (II, § 124):

[...] Em primeiro lugar, carece de uma lei estabelecida, recebida e aceita mediante o consentimento comum enquanto padrão de probidade e da improbidade, e medida comum para solucionar todas as controvérsias entre eles (LOCKE, 1998, p. 496). 
Embora as leis naturais são percebidas por todos os seres racionais, o homem por ser influenciado pelas suas ambições não consegue reconhecê-las de forma correta, assim, o governo civil ao obrigá-las através da lei formal, proporciona estabilidade em relação às expectativas da aplicação do direito, ou seja, a lei estabelecida dirá ao homem qual será a reprovação ou que tipo de sanção ele sofrerá para seus atos criminosos, as pessoas saberão de antemão, antes de cometer um delito qual será o seu castigo, ao contrário do que ocorre no estado de natureza, onde um indivíduo movido pelas suas paixões poderia repelir uma ofensa contra sua pessoa de forma imparcial, aplicando um castigo desproporcional a ofensa sofrida.

O governo civil também oferece um juiz conhecido e imparcial, uma pessoa que conhece a norma positivada, e que por ser terceiro, poderá julgar sem estar influenciado pelo calor da relação litigiosa, aplicando a regra com justiça e equidade. $O$ fato das pessoas saberem quem é o juiz e ele estar investido de autoridade pelo próprio pacto social traz uma segurança e um alento para ambas as partes de uma demanda, pois estarão cientes que o juiz não privilegiará ninguém a não ser pela imposição da lei.

[...] carece o estado de natureza de um juiz conhecido e imparcial, com autoridade para solucionar todas as diferenças de acordo com a lei estabelecida. Pois sendo cada um, nesse estado, juiz e executor da lei da natureza ao mesmo tempo, e por serem os homens parciais em favor de si próprios, a paixão e a vingança tendem a levá-los muito longe, e com ardor demasiado, em seus próprios pleitos, da mesma foram que a negligência e a indiferença os tornam demasiado descuidados quando se trata de terceiros (LOCKE, 1998, p. 496-497).

Outra vantagem do governo civil que John Locke aponta, é que as decisões acerca das diferenças entre os indivíduos têm legitimidade e apoio de um poder delegado pelas próprias pessoas, antes, no estado de natureza, o homem poderia fazer justiça com a força das próprias mãos, mas quem lhe daria as garantias de que ele fazendo isto não poderia sofrer as sanções de outras pessoas? E, se quem é ofendido não possuir forças superiores daquele que ofende, ele não terá direito de aplicar o castigo? Qual o apoio que o homem teria para legitimar suas decisões? Nenhum no estado de natureza.

Mas quando o homem firmou o pacto social, deu forças legítimas ao governo de apoiar e garantir as sanções aplicadas, mas agora quem aplica os castigos não é mais o 
ofendido, e sim o próprio governo, pois trazendo para si esta responsabilidade, evita-se também o espírito de vingança que nasce mesmo naquele que comete o crime e é punido.

[...] o estado de natureza freqüentemente carece de um poder para apoiar e sustentar a sentença quando justa e dar a ela a devida execução. Aqueles que cometeram alguma injustiça dificilmente deixarão, quando lhes for possível, de fazer valer, pela força, sua injustiça: tal resistência torna a punição amiúde perigosa e não raro destrutiva aos que tentam aplicá-la (LOCKE, 1998, p. 497).

O governo civil institucionalizado desta forma age em prol da lei e da justiça, pois individualmente o homem se move por interesses, e nunca seria totalmente justo e imparcial.

John Locke ainda faz uma interessante observação, que embora o pacto social crie esta força superior, não implica que aquele está submisso a este, ou seja, se a sociedade organizada não trouxer as garantias que o homem pagou com a sua liberdade que tinha no estado de natureza; se ela não resolver os problemas que existem neste estado, os homens também têm o direito de revolta, depondo qualquer governante que utilize as forças legítimas do governo em prol de interesses que sejam divergentes daqueles propostos pelo pacto social, que são: garantir a propriedade e a segurança da pessoa.

Onde não existe a administração de justiça para a garantia dos direitos dos homens e tampouco nenhum poder restante no seio da comunidade para dirigir a força ou prover as necessidades do público, com certeza não resta governo algum. Onde as leis não podem ser executadas é como se não houvesse leis, e um governo sem leis é, suponho, um mistério político, inconcebível para a capacidade humana e incompatível com a sociedade humana (LOCKE, 1998, p. 578).

Em suma, qualquer que seja o governo ou a sua forma, ele deverá garantir acima de tudo, a conservação da propriedade privada, pois para John Locke esta é a única premissa legítima para dar condição à sua existência.

\section{Conclusão}

De acordo com a leitura do Segundo Tratado sobre o Governo Civil, o homem em seu estado de natureza vive em liberdade para decidir seus atos e dispor de suas posses de acordo com sua conveniência. Vive também em igualdade pelo fato de que criaturas de 
mesma espécie e posição, que nascem com as mesmas vantagens da natureza, possuem por reciprocidade o poder e jurisdição, não tendo ninguém mais do que outro qualquer. (II, § 4).

Este estado é um estado de liberdade, mas não de licenciosidade, e por isto impõe certas regras, que são as leis da natureza: Ninguém poderá lesar a outrem em suas vidas, saúde, liberdade e bens. No entanto, embora os homens tenham percebido que devam agir de acordo com estas normas, ele ao decidir suas ações ou recriminar as dos outros, poderá estar sendo influenciado pelas suas paixões e pelos seus valores subjetivos, que traz um grande inconveniente para a harmonia e a justiça no convívio em comunidade, pois sendo o indivíduo o julgador e executor destas leis, poderá usá-las de maneira imparcial e injusta.

Para superar esta instabilidade existente no estado de natureza e trazer uma expectativa de justiça que garanta seus direitos adquiridos, os indivíduos convencionam um pacto social para criar uma sociedade organizada politicamente e que traga as respostas e soluções para as carências apontadas no estado natural.

John Locke chama esta sociedade politicamente organizada de governo civil, que surge pelo pacto entre as pessoas, que consentem em abdicar as suas liberdades irrestritas pela submissão da lei clara e conhecida por todos; de um juiz imparcial para aplicá-las; e de um poder legítimo para dar apoio às sanções, pois somente desta forma as suas vidas, liberdades e bens (que são as propriedades privadas, II, § 123.), poderão ser garantidas.

\section{Referências}

AMARAL. Aspectos econômicos e sociais da integração de mercados. Globalização e integração de mercados: Repercussões sociais. In.: SEMINÁRIO BRASIL SÉCULO XXI - O DIREITO NA ERA DA GLOBALIZAÇÃO MERCOSUL: ALCA E UNIÃO EUROPÍEA: PALESTRAS. Brasília: OAB Conselho Federal, 2002.

COBRA, Rubem Queiroz. Teoria do Conhecimento, Teoria Política, Economia, Religião, Educação e Principais obras. Disponível em: <http://www.cobra.pages.nom.br/fmplocke.html>. Acesso em: 06 maio 2007.

LOCKE, John. Dois tratados sobre o governo. São Paulo: Martins Fontes, 1998.

YOLTON, John W. Dicionário de filósofos, Locke. Rio de Janeiro: Jorge Zahar Editor, 1996. 